\title{
Role of transoesophageal echocardiography in the diagnosis and management of aortic root abscess
}

\author{
Dominic Y C Leung, Gregory B Cranney, Andrew P Hopkins, Warren F Walsh
}

\begin{abstract}
Objective-To assess and compare the roles of transthoracic and transoesophageal echocardiography in the diagnosis and management of an aortic root abscess.

Design-To select patients with echocardiographic diagnosis of aortic valve endocarditis with and without an aortic root abscess and correlate this with a retrospective review of surgical and necropsy data.
\end{abstract}

Setting-Tertiary referral centre at a university teaching hospital.

Patients and methods-34 patients with confirmed aortic valve endocarditis were treated over a four and a half year period. All patients underwent both transthoracic and transoesophageal echocardiography with 17 patients having biplane or multiplane imaging.

Result-11 patients (32\%) had an aortic root abscess. Transthoracic echocardiography identified four cases of aortic root abscess whereas transoesophageal echocardiography correctly detected all 11 cases and also detected complications including mitral aortic intervalvar fibrosa fistula in two patients and right atrial involvement in another two patients. Only biplane imaging was able to show an anterior aortic root abscess in one patient and the circumferential involvement of the aortic annulus in another two patients. All patients with an aortic root abscess were treated surgically after transoesophageal echocardiographic diagnosis. After operation, prosthetic aortic regurgitation was present in seven patients and a repeat operation was performed in three patients. Only transoesophageal echocardiography detected a postoperative aorto-right atrial fistula in two patients and recurrence of the root abscess in another. There were five deaths in hospital (45\%). Conclusions-Compared with transthoracic echocardiography, transoesophageal echocardiography was more sensitive and more specific for the early diagnosis of aortic root abscess and its complications and facilitated both the preoperative and postoperative management of these patients. Biplane and multiplane imaging provide additional diagnostic information. All patients with suspected aortic valve endocarditis should have an early transoesophageal echocardiographic study.

(Br Heart f 1994;72:175-181)

Transthoracic echocardiography has traditionally been the investigation of choice for the detection of valvar vegetations, the assessment of associated valvar dysfunction, and other complications in patients with infective endocarditis. ${ }^{1-3}$ Its reduced diagnostic sensitivity and inadequate image quality in some patients, however, especially those with prosthetic valves, remain important limitations.

Infection of the aortic valve may extend into the annulus and the mitral aortic intervalvar fibrosa resulting in the formation of an aortic root abscess. These structures are relatively avascular and offer little resistance to infection. In necropsy and surgical series, this serious complication has been reported in up to $40 \%$ of patients with native aortic valve endocarditis and the incidence is higher in patients with prosthetic aortic valve endocarditis. ${ }^{4-6}$ As the presence of an aortic root abscess is usually an indication for urgent surgery, its prompt and accurate diagnosis is essential if perioperative morbidity and mortality are to be reduced and surgical repair facilitated. Aortic root abscess has often been difficult to diagnose preoperatively by transthoracic echocardiography. Transoesophageal echocardiography, with its better image quality due to the close proximity to cardiac structures and the use of a higher frequency transducer, has been shown to be better than transthoracic echocardiography in the detection of valvar vegetations ${ }^{7}$ and the assessment of associated dysfunction of the prosthetic valve. ${ }^{8}$

There is little information available on the role of transoesophageal echocardiography in the detection and management of aortic root abscess and its complications. ${ }^{910}$ Therefore, the aim of our study was to assess the role of transoesophageal echocardiography in the diagnosis and management of an aortic root abscess both before and after surgical intervention.

\section{Patients and methods} PATIENTS

Between January 1989 and May 1993, a total of 234 patients with suspected infective endocarditis were referred to our echocardiography
Cleveland, Avenue,

Accepted for publication 4 January 1994 
laboratory for transoesophageal echocardiography. Thirty four consecutive patients with proved aortic valve endocarditis were identified and this group formed our study population.

\section{ECHOCARDIOGRAPHY}

All patients had both transthoracic and transoesophageal echocardiography. Transthoracic echocardiography was performed with 2.5 $\mathrm{MHz}$ and 3.5 $\mathrm{MHz}$ phased array transducers with a Hewlett Packard Sonos 1000 system (Hewlett Packard, Andover, Massachusetts). Systematic examinations were performed from all the standard echocardiographic windows. Transoesophageal echocardiography was performed immediately after the transthoracic study with a $5 \mathrm{MHz}$ transducer mounted at the tip of a modified gastroscope according to standard protocols. ${ }^{11}$ Monoplane imaging was performed in 17 patients, biplane in 14, and multiplane in three. All patients gave written informed consent. All patients fasted for at least four hours before the examination and were sedated with intravenous fentanyl and midazolam. The oropharynx was anaesthetised with $10 \%$ xylocaine spray. There were no complications.

Aortic valve endocarditis was considered to be proved when a new vegetation or root abscess was detected at the aortic valve together with either positive blood cultures or symptoms and signs of sepsis when blood culture was negative. An aortic root abscess was considered to be present when there were echolucent cavities in the perivalvar region or abnormal perivalvar echodensity identified in more than one tomographic plane when endocarditis was suspected. ${ }^{91012}$ Complications of the aortic root abscess such as formation of an aneurysm or fistula were sought. The severity of aortic regurgitation was assessed semiquantitatively by colour and pulsed wave Doppler and was graded as nil, trivial, mild, moderate, or severe according to the criteria of Perry et al. ${ }^{13}$

\section{ANATOMICAL CORRELATION}

Surgical records of all patients with infective endocarditis undergoing open heart surgery and necropsy studies of all patients who died of infective endocarditis during the same period were reviewed. The presence, site, and extent of aortic root abscess were examined by direct inspection at surgery or necropsy and confirmed by histopathological examination as an area of necrosis with purulent material at or extending from the aortic valve annulus.

\section{FOLLOW UP}

All patients with an aortic root abscess who were discharged from hospital were followed up. Patients, their general practitioners, and attending physicians were contacted and events after discharge were recorded.

\section{Results}

There were 34 patients with proved aortic valve endocarditis. The mean age was 52,24 were men, and 10 were women. Staphylococcus aureus was the most common causative organism (nine patients, $26 \%$ ). Six patients (18\%) had culture negative aortic valve endocarditis (previous antibiotic treatment in three). Staphylococcus epidermidis was the causative organism in four patients (12\%), viridans type streptococci in five $(15 \%)$, other non-viridans streptococci in five $(15 \%)$, gram negative organisms in three (9\%), Candida albicans in one patient, and clostridial species in another. The underlying aortic valve was native tricuspid aortic valve in 23 patients $(65 \%)$, bicuspid aortic valve in three $(6 \%)$, heterograft in five (18\%), St Jude prosthesis in two (9\%), and Starr-Edwards prosthesis in one. Twenty three patients were treated surgically and there were eight deaths in hospital (overall mortality rate $18 \%$ ).

Aortic root abscess was confirmed either at surgery or necropsy in 11 patients $(32 \%$, table 1). Of these 11 patients, six were found to have vegetations on the aortic valve, the mean (range) age was 48 (16-79), and there were 10 men and one woman. The mean (range) duration of symptoms before diagnosis of aortic root abscess was $4.6(1-12)$ weeks. $S$ aureus was the causative organism in five of the 11 patients $(45 \%)$. The underlying aortic valve was a porcine heterograft in four $(36 \%)$, St Jude prosthesis in two (27\%), bicuspid aortic valve in three $(27 \%)$, and native tricuspid aortic valve in two $(18 \%)$.

Table 1 Clinical findings and outcome of the 11 patients with aortic root abscess

\begin{tabular}{|c|c|c|c|c|c|c|}
\hline Patient & Sex/age & Aortic valve & Organism & $\begin{array}{l}\text { Duration } \\
\text { (weeks) }\end{array}$ & Surgery & Follow up \\
\hline $\begin{array}{l}1 \\
2\end{array}$ & $\begin{array}{l}\mathrm{F} / 68 \\
\mathrm{M} / 47\end{array}$ & $\begin{array}{l}\text { Heterograft } \\
\text { Heterograft }\end{array}$ & $\begin{array}{l}\text { Candida } \\
\text { Staph aureus }\end{array}$ & $\begin{array}{l}4 \\
3\end{array}$ & $\begin{array}{l}\text { Death on induction } \\
\text { AVR, root repair }\end{array}$ & $\begin{array}{l}\text { Death in hospital } \\
\text { Death in hospital }\end{array}$ \\
\hline 3 & $\mathrm{M} / 47$ & Bicuspid & Staph aureus & 2 & $\begin{array}{l}\text { AVR, MVR, } \\
\text { root repair }\end{array}$ & $\begin{array}{l}\text { AR, abscess, Ao-LA } \\
\text { fistula, reop, death in hospital }\end{array}$ \\
\hline 4 & $\mathrm{M} / 62$ & Native tricuspid & Staph aureus & 1 & AVR, root repair & $\begin{array}{l}\text { AR, CHB, Ao-RA fistula, } \\
\text { death in hospital }\end{array}$ \\
\hline 5 & $\mathbf{M} / 57$ & Native tricuspid & Strep pneumoniae & 2 & AVR, root repair & $\begin{array}{l}\text { AR, CHB, Ao-RA fistula, } \\
\text { death in hospital }\end{array}$ \\
\hline $\begin{array}{l}6 \\
7 \\
8 \\
9 \\
10 \\
11\end{array}$ & $\begin{array}{l}M / 59 \\
M / 37 \\
M / 79 \\
M / 16 \\
M / 24 \\
M / 30\end{array}$ & $\begin{array}{l}\text { St Jude's } \\
\text { St Jude's } \\
\text { Heterograft } \\
\text { Bicuspid } \\
\text { Heterograft } \\
\text { Bicuspid }\end{array}$ & $\begin{array}{l}\text { Staph epidermidis } \\
\text { Culture negative } \\
\text { Clostridia } \\
\text { Staph aureus } \\
\text { Staph aureus } \\
\text { Viridans streptococci }\end{array}$ & $\begin{array}{r}12 \\
6 \\
12 \\
2 \\
2 \\
6\end{array}$ & $\begin{array}{l}\text { AVR, root repair } \\
\text { Homograft aortic root } \\
\text { AVR, root repair } \\
\text { AVR, root repair } \\
\text { Homograft aortic root } \\
\text { AVR }\end{array}$ & $\begin{array}{l}\text { Discharged, AR } \\
\text { Discharged } \\
\text { Discharged } \\
\text { Discharged, late reop for AR } \\
\text { Discharged, AR } \\
\text { Discharged, late reop for AR }\end{array}$ \\
\hline
\end{tabular}

Abscess, recurrence of aortic root abscess after surgery; Ao-LA fistula, aorto-left atrial fistula; Ao-RA fistula, aorto-right atrial fistula; AR, aortic regurgitation; AVR, aortic valve replacement; CHB, complete heart block; Duration, duration of symptoms before diagnosis of abscess; MVR, mitral valve replacement; Reop, reoperation; Root repair, repair of aortic root with bovine pericardium; Staph, Staphylococcus; Strept, Streptococcus. 
Table 2 Comparisonm of preoperative transthoracic (TTE) and transoesophageal (TOE) echocardiographic findings of the 11 patients with aortic root abscess

\begin{tabular}{|c|c|c|}
\hline Patient & $T T E$ & $T O E$ \\
\hline 1 & $\begin{array}{l}\text { Aortic root abscess, AV vegetation, } \\
\text { no AR }\end{array}$ & $\begin{array}{l}\text { Aortic root abscess, } \\
\text { AV vegetation, no AR }\end{array}$ \\
\hline 2 & Aortic root abscess, severe AR & $\begin{array}{l}\text { Aortic root abscess, severe periprosthetic } \\
\text { AR }\end{array}$ \\
\hline 3 & $\begin{array}{l}\text { AV vegetation, mild AR, } \\
\text { thickening of base of AML }\end{array}$ & $\begin{array}{l}\text { Aortic root abscess, AV vegetation, } \\
\text { mild AR, } \\
\text { MAIVF aneurysm, fistula }\end{array}$ \\
\hline 4 & AV vegetation, mild $A R$ & $\begin{array}{l}\text { Aortic root abscess, AV vegetation, mild } \\
\text { AR, RA wall vegetation }\end{array}$ \\
\hline 5 & $A V$ vegetation, severe $A R$ & $\begin{array}{l}\text { Aortic root abscess, AV vegetation, } \\
\text { severe } A R, R A \text { wall vegetation }\end{array}$ \\
\hline 6 & Moderate AR & $\begin{array}{l}\text { Aortic root abscess, moderate } \\
\text { periprosthetic AR }\end{array}$ \\
\hline 7 & Trivial AR, thickening of base of AML & $\begin{array}{l}\text { Aortic root abscess, trivial AR, MAIVF } \\
\text { aneurysm, fistula }\end{array}$ \\
\hline 8 & Mild AR & $\begin{array}{l}\text { Aortic root abscess, mild periprosthetic } \\
\text { AR }\end{array}$ \\
\hline 9 & Aortic root abscess, mild AR & $\begin{array}{l}\text { Aortic root abscess, } \mathrm{AV} \text { vegetation, mild } \\
\mathrm{AR}\end{array}$ \\
\hline 10 & Aortic root abscess, moderate AR & $\begin{array}{l}\text { Aortic root abscess, moderate } \\
\text { periprosthetic AR }\end{array}$ \\
\hline 11 & Severe AR & $\begin{array}{l}\text { Aortic root abscess, severe AR, AV } \\
\text { vegetation }\end{array}$ \\
\hline
\end{tabular}

AML, anterior mitral leaflet; AV, aortic valve; AR, aortic regurgitation; MAIVF, mitral aortic intervalvular fibrosa; $R A$, right atrium.

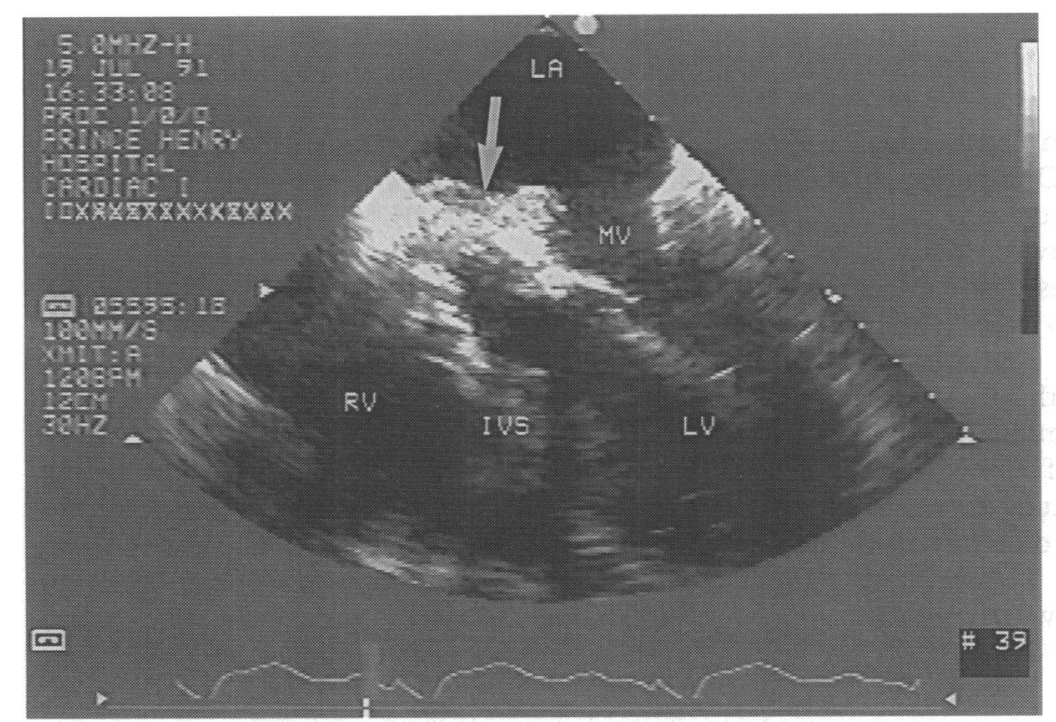

Figure 1 Aortic root abscess (arrow) affecting the posterior region of the aortic annulus : transoeophageal echocardiography (horizontal plane). IVS, interventricular septum; LA, left atrium; $L V$, left ventricle; $M V$, mitral valve; $R V$, right ventricle.

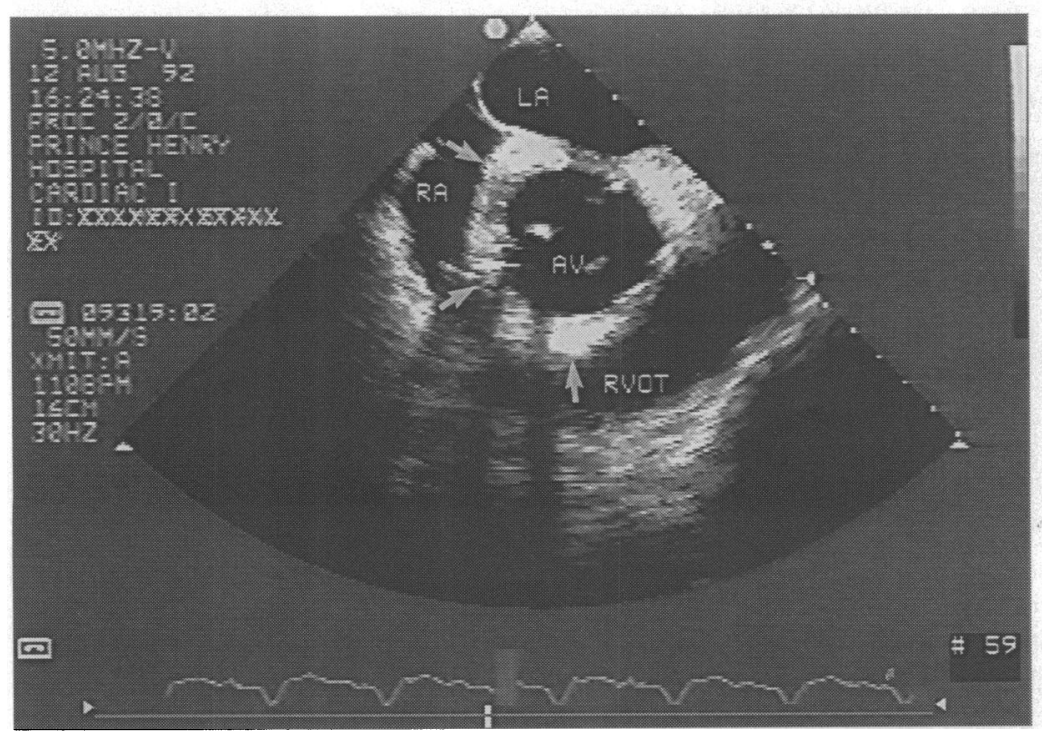

Figure 2 Transoesophageal echocardiography (longitudinal plane) showing a diffusely thickened aortic annulus (arrows) consistent with circumferential involvement by the root abscess. $A V$, aortic valve (St fude); $L A$, left atrium; $R A$, right atrium; $R V O T$, right ventricular outflow tract.
PREOPERATIVE ECHOCARDIOGRAPHIC FINDINGS Table 2 shows the results of the echocardiographic studies in the 11 patients with confirmed aortic root abscess. Of the six patients who had vegetations on the aortic valve at surgery or necropsy, the vegetations were seen by transthoracic echocardiography in four patients (sensitivity 66\%) and in all six patients by transoesophageal echocardiography. Associated aortic regurgitation was trivial in two, mild in four, moderate in two, and severe in three.

Only four of the 11 cases of aortic root abscess were correctly identified by transthoracic echocardiography (sensitivity $36 \%$ ). By contrast, transoesophageal echocardiography detected all 11 cases of aortic root abscess (sensitivity $100 \%$ ). The most common site for an aortic root abscess was the posterior region of the aortic annulus (fig $1, n=7$ ). In two other patients the whole aortic annulus was involved resulting in aortoventricular discontinuity. The annulus in the region of the left coronary cusp was involved in one patient and the anterior half of the annulus in another. The echocardiographic appearances of aortic root abscess ranged from a diffusely thickened aortic root in early cases to multiple echolucent spaces near the aortic annulus in more advanced cases.

Four of the 11 patients with aortic root abscess had monoplane transoesophageal imaging and seven had biplane examination. The longitudinal plane image available in these seven patients provided considerable additional information. Biplane imaging was able to diagnose aortoventricular discontinuity in two patients by clearly showing the anterior extension of the aortic root abscess in the longitudinal plane (fig 2). In patient 5 , the aortic root abscess was seen only in the longitudinal plane due to its anterior location (fig $3)$. In all four patients with prosthetic aortic regurgitation (patients $2,6,8,10$ ), the longitudinal plane showed the site of periprosthetic aortic regurgitation to be in the posterior aortic annulus.

Only transoesophageal echocardiography detected local complications of aortic root abscess in four patients. In two patients, the aortic root abscess resulted in an aneurysm of the mitral aortic intervalvar fibrosa that had ruptured into the left atrium leading to formation of a fistula (patient 3, 7, fig 4). In another two patients, the membranous ventricular septum was involved and an echodense mass was seen extending from the aortic annulus into the right atrial cavity (patients 4, 5). These findings were all subsequently confirmed at operation.

CLINICAL COURSE

All patients with an aortic root abscess were treated surgically. Two patients had homograft aortic root and valve replacement with reimplantation of the coronary arteries (patients 7,10 ). Six patients had aortic valve replacement and reconstruction of the aortic root with bovine pericardium (patients $2,4,5,6,8,9)$. One patient had mitral and 


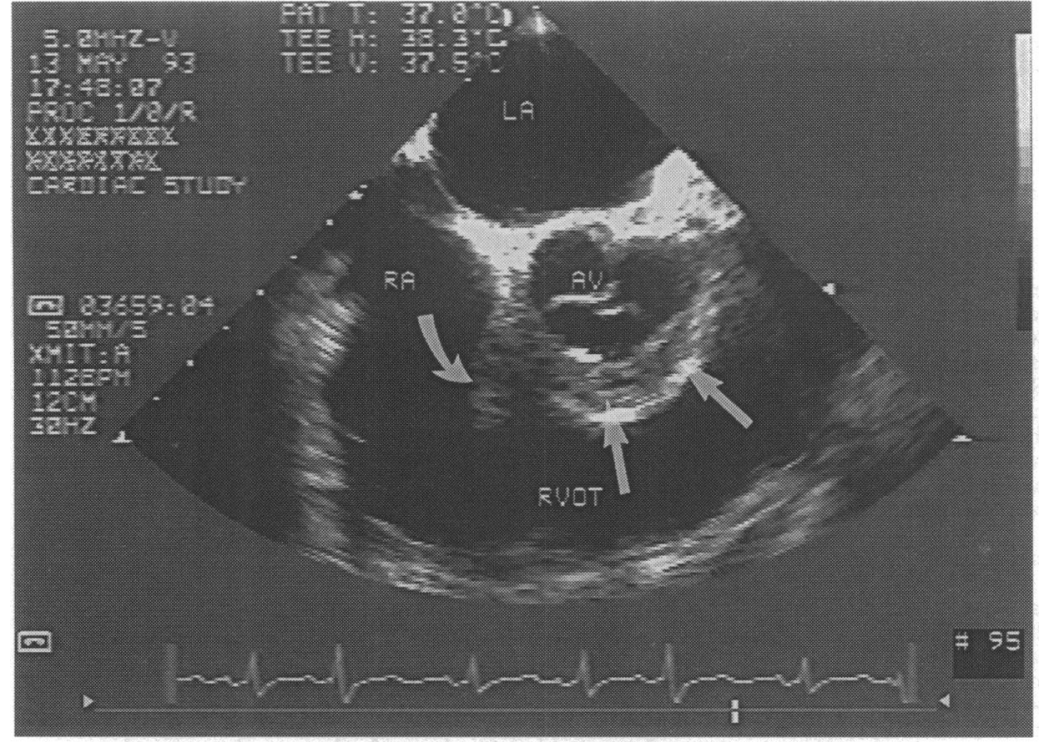

Figure 3 Aortic root abscess (straight arrows) affecting the anterior half of the aortic annulus : transoesophageal echocardiography (longitudinal plane). Curved arrow: vegetation extending from the aortic annulus onto the right atrial wall. $A V$, native tricuspid aortic valve; other abbreviations as for fig 2.

aortic valve replacement with repair of the aortic root (patient 3). One patient had aortic valve replacement with debridement and closure of the abscess cavity (patient 11). St Jude's valve prostheses were used in all patients except the two who had homograft replacement.

There were five deaths in hospital in the aortic root abscess group (mortality $45 \%$ ). Three patients died of uncontrolled sepsis with an intracardiac fistula (patients $3,4,5$ ). One critically ill patient died during induction of anaesthesia (patient 1), and one patient died of postoperative low cardiac output syndrome on day 1 (patient 2).
ROLE OF TRANSOESOPHAGEAL

ECHOCARDIOGRAPHY IN PREOPERATIVE

MANAGEMENT

The diagnosis of aortic root abscess was made by transoesophageal echocardiography within 24 hours of admission in eight patients. In the remaining three patients diagnosis was delayed because of delay in referral for transoesophageal echocardiography after initial negative transthoracic studies. All 11 patients were referred for consideration of surgery after the diagnosis of aortic root abscess was made by transoesophageal echocardiography. Surgery was recommended in five patients on the basis of transoesophageal echocardiographic finding of the presence of an aortic root abscess alone without significant aortic regurgitation. In the remaining six patients, surgery was undertaken based on the transoesophageal echocardiographic findings of both an aortic root abscess and important aortic regurgitation. Six patients had urgent surgery within 36 hours of the transoesophageal echocardiographic diagnosis. Surgery was delayed in five patients because of the need to refer the patients to another hospital for homograft aortic root replacement in two cases, the need for drainage of a complicating cerebral abscess in one case and low virulence of causative organism and the desire to establish antibiotic treatment in two cases.

\section{POSTOPERATIVE ECHOCARDIOGRAPHIC} FINDINGS

Transthoracic echocardiographic studies were performed in nine patients and transoesophageal studies in seven patients after operation. All postoperative studies were performed within two weeks of the operation except for the two patients who had homograft aortic root replacement at another hospi-
Figure 4

Transoesophageal echocardiography (horizontal plane) showing a mitral aortic intervalvar fibrosa aneurysm (curved arrow) that has ruptured into the left atrium $(L A)$ resulting in a fistula depicted by an abnormal jet (straight arrow) on colour Doppler map in systole. Abbreviations as for fig 1 .

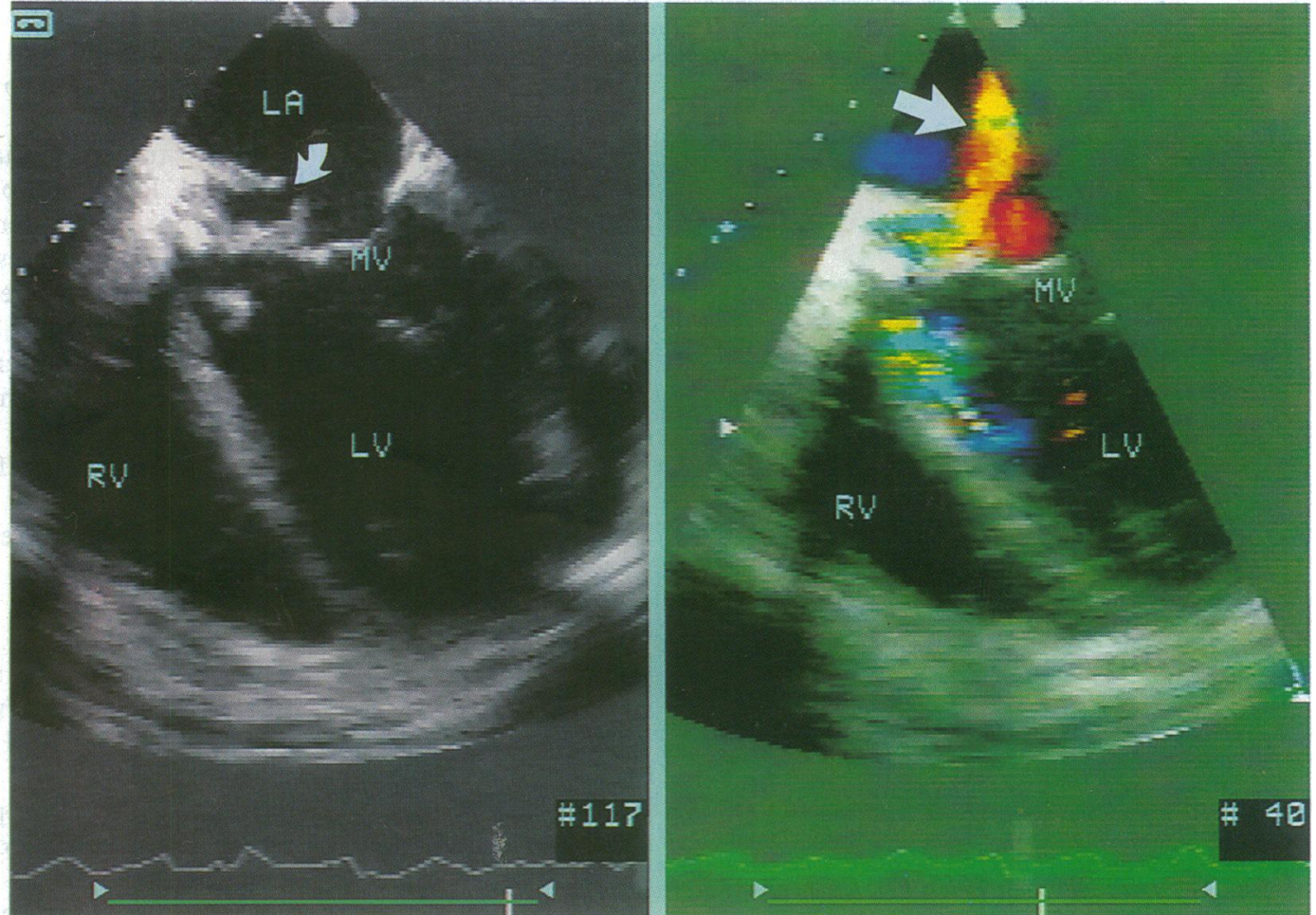


Figure 5

Transoesophageal

echocardiography

(longitudinal plane)

showing an aorto-right

atrial fistula (curved

arrow) depicted by an

abnormal colour jet

(straight arrows) on colour Doppler map in systole. $A V$; aortic valve (St

fude); TV, tricuspid valve; other abbreviations as for figs 1 and 2 .

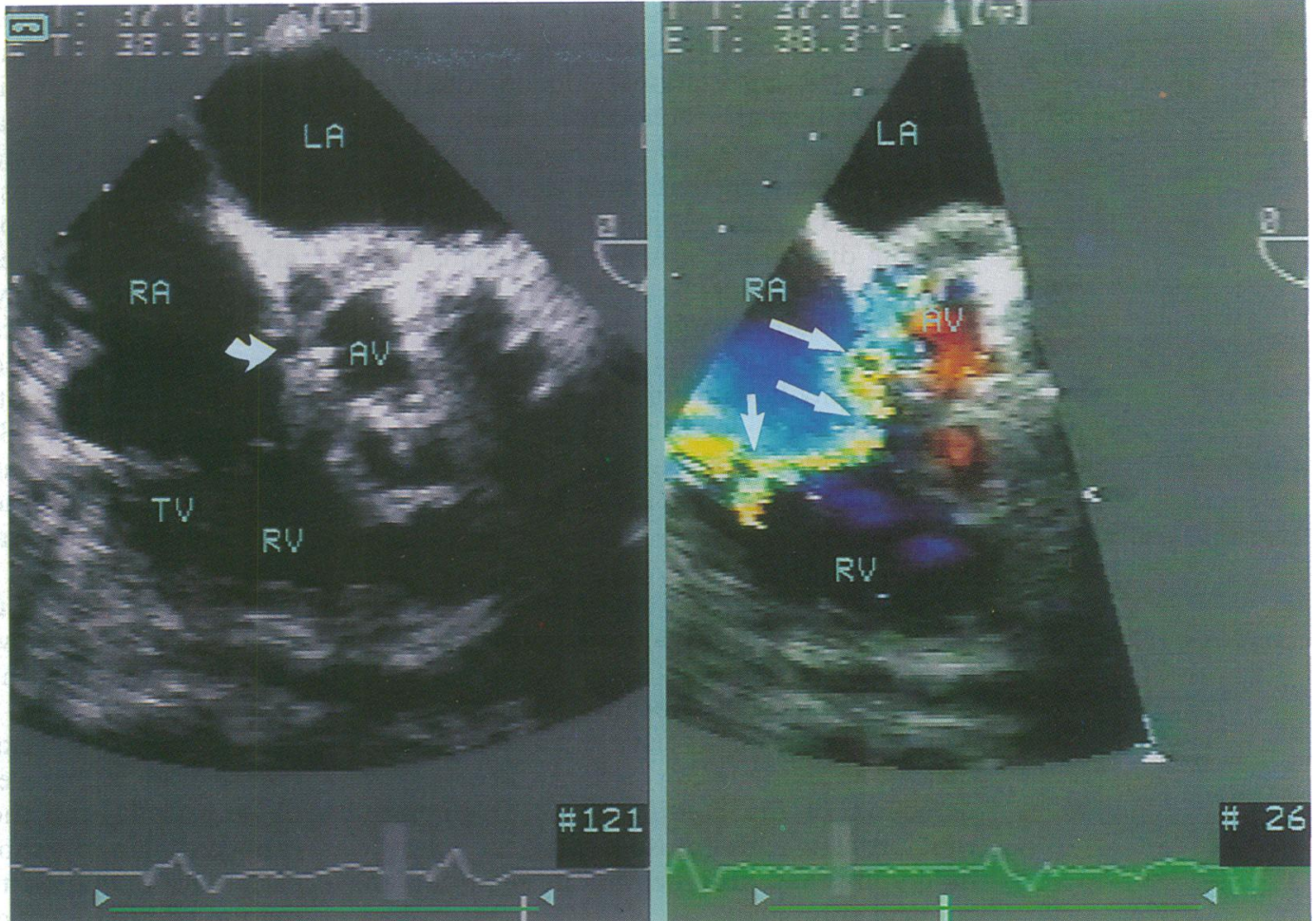

tal. Transthoracic echocardiography detected moderate prosthetic aortic regurgitation in five patients but did not show mild prosthetic aortic regurgitation in another two patients. By contrast, transoesophageal echocardiography clearly showed the periprosthetic site of aortic regurgitation in all the patients with postoperative aortic regurgitation. Transoesophageal echocardiography correctly showed postoperative aorto-right atrial fistula in two patients (patients 4, 5, fig 5). Transthoracic echocardiography did not show the fistula in patient 4 and incorrectly diagnosed a ventricular septal defect in patient 5 . Recurrence of the aortic root abscess with dehiscence of the aortic prosthesis was detected by transoesophageal echocardiography but not by transthoracic echocardiography in patient 3. A repeat operation was performed for recurrent aortic root abscess in this patient and for severe postoperative periprosthetic aortic regurgitation in two other patients (patients 9,11).

LONG TERM FOLLOW UP

The mean (range) duration of follow up was 21 (4-46) months for the six patients who were discharged from hospital. At the time of follow up, all six patients were in New York Heart Association functional class I with no evidence of recurrence of endocarditis. Moderate aortic regurgitation was present in two patients (patients 6,10 ).

\section{Discussion}

Aortic root abscess complicating aortic valve endocarditis is associated with high mortality and morbidity. ${ }^{1415}$ Our study shows that transoesophageal echocardiographic imaging greatly facilitated the preoperative and post- operative diagnosis and management of aortic root abscesses in our patients and that the availability of biplane imaging offered considmonoplane imaging. To the best of our knowledge, this is the largest reported series of patients in whom transoesophageal echocardiography was used for the detection of an aortic root abscess and in which most of the patients underwent biplane or multiplane examination.

\section{INCIDENCE OF AORTIC ROOT ABSCESS}

Arnetts and Roberts found an aortic valve ring abscess at necropsy in 21 of 52 patients $(49 \%)$ with native aortic valve endocarditis, and in all 15 patients $(100 \%)$ with prosthetic aortic valve endocarditis. ${ }^{4}$ In a later necropsy series of 59 patients with aortic valve endocarditis reported by the same workers, 24 patients (41\%) had a root abscess. ${ }^{5}$ The overall incidence of aortic root abscess in aortic valve endocarditis in our series of patients was $32 \%$ with the incidence of this complication in the presence of an aortic prosthesis being $60 \%$.

\section{PREVIOUS ECHOCARDIOGRAPHIC STUDIES}

Before the advent of transoesophageal echocardiography, transthoracic echocardiography had been reported to be useful in the detection of an aortic root abscess before operation $^{121617}$ with a reported sensitivity for the detection of an aortic root abscess ranging from $18 \%$ to $67 \% .^{1018}{ }^{19}$ Karalis et al reported the use of transoesophageal echocardiography in detecting subaortic complications of aortic valve endocarditis in 24 cases, ${ }^{9}$ but they did not specifically examine the role of transoesophageal echocardiography in the management of these patients. Moreover, the sensitivity of transoesophageal echocardiograerably more information compared with 
phy in diagnosing these complications could not be determined because only patients with subaortic complications documented on transoesophageal echocardiography were included in the study. In another series of patients described by Daniel et al, the overall sensitivity of transoesophageal echocardiography for diagnosing abscesses associated with endocarditis was $\mathbf{8 7 \%}$ and the specificity was $94.6 \% .^{10}$ Transoesophageal echocardiography did not detect an aortic root abscess in four of the 26 patients with this complication (sensitivity $85 \%$ ). The lower sensitivity in this series compared with ours may have been due to the use of only monoplane imaging in all cases.

\section{ROLE OF TRANSOESOPHAGEAI}

\section{ECHOCARDIOGRAPHY IN MANAGEMENT}

Early preoperative diagnosis of aortic root abscess in our patients was made possible by transoesophageal echocardiography without which surgery might have been considerably delayed in many of our patients. Preoperative detection of the complications of an aortic root abscess with transoesophageal echocardiography was also helpful in planning the surgical approach.

Transthoracic echocardiography has important limitations after operation due to artefacts and masking of colour flow by prosthetic material and image degradation from mechanical ventilation. Transoesophageal echocardiography was able to overcome these difficulties, providing valuable information about the site of periprosthetic regurgitation, recurrence of the root abscess, or development of a fistula.

\section{MONOPLANE V BIPLANE TRANSOESOPHAGEAI ECHOCARDIOGRAPHY}

With the biplane probe, the aortic valve could be seen in both the short and the long axes in most patients in the longitudinal imaging plane when the probe tip was flexed laterally. Biplane imaging was especially important in detecting involvement of the anterior aortic root annulus by the abscess, which was poorly seen by conventional monoplane imaging. The longitudinal plane provided the only means of detecting the root abscess in one patient and accurately defined the involvement of the circumference of the annulus in two other patients.

\section{LIMITATIONS OF OUR STUDY}

The sensitivity and specificity of transoesophageal echocardiography in our study in diagnosing aortic root abscesses in patients with surgical or necropsy corroboration was $100 \%$. Of the 34 patients with proved aortic valve endocarditis, 10 were managed medically and there was one death in hospital and one late death. Necropsy studies on these two patients did not show an aortic root abscess. Eight patients were managed medically and it was therefore possible that an aortic root abscess may have been missed by transoesophageal echocardiography in these patients. Their favourable clinical course with antibiotic treatment alone makes the presence of an aortic root abscess very unlikely. The small number of patients with an aortic root abscess treated in a single referral centre, and the fact that a few early patients had monoplane transoesophageal echocardiography were other limitations of this study.

In conclusion, in patients with aortic valve endocarditis, transoesophageal echocardiography is highly sensitive and specific in detecting the presence, location, and extent of an aortic root abscess and in detecting complications of an aortic root abscess such as formation of a fistula. Biplane and multiplane imaging are better than monoplane imaging in showing the involvement of the anterior aortic root annulus. Thus transoesophageal echocardiography facilitates both the preoperative and postoperative management of these patients. Therefore, we strongly recommend that all patients with suspected aortic valve endocarditis should have transoesophageal echocardiographic examination early in the course of their illness especially in the presence of an aortic prosthesis. Transoesophageal echocardiography should also be performed early after operation to obtain baseline information and to detect complications.

We thank Dr Lincoln Lee for performing some of the earlier transoesophageal echocardiography studies and Cathie Hall, David Law, Kim Touzel, and Beverley Jacobson for performing Drans

1 Stewart JA, Silimperi D, Harris P, Wise NK, Fraker TD, Kisslo JA. Echocardiographic documentation of vegetative lesions in infective endocarditis: clinical implications. Circulation 1980;61:374-80.

2 Martin RP, Meltzer RS, Chia BL, Stinson EB, Rakowski H, Popp RL. Clinical utility of two-dimensional echocardiography in infective endocarditis. Am $\mathcal{F}$ Cardiol 1980;46:379-85.

3 Sanfilippo AJ, Picard MH, Newell BA, Rosas E, Davidoff $\mathrm{R}$, Thomas JD, et al. Echocardiographic assessment of patients with infectious endocarditis: prediction of risk for complications. $¥ \mathrm{Am}$ Coll Cardiol 1991;18:1191-9.

4 Arnett EN, Roberts WC. Clinicopathologic analysis of 22 necropsy patients with comparison of observations in 74 necropsy patients with active endocarditis involving necropsy patients with active endocarditis involving 281-92.

5 Arnett EN, Roberts WC. Valve ring abscess in active endocarditis. Frequency, location, and clues to clinical diagnosis from the study of 95 necropsy patients. Circulation nosis from the st.

6 John RM, Pugsley W, Treasure T, Sturridge MF, Swanton RH. Aortic root complications of infective endocarditis-influence on surgical outcome. Eur Heart $\mathcal{f} 1991$; tis-influe

7 Shively BK, Gurule FT, Roldan CA, Leggett JH, Schiller NB. Diagnostic value of transesophageal compared with transthoracic echocardiography in infective endocarditis. f Am Coll Cardiol 1991;18:391-7.

8 Nellessen U, Schnittger I, Appleton CP, Masuyama T, Bolger A, Fischell TA, et al. Transesophageal twodimensional echocardiography and color Doppler flow velocity mapping in the evaluation of cardiac valve prostheses. Circulation 1988;78:848-55.

9 Karalis DG, Bansal RC, Hauck AJ, Ross JJ, Applegate PM, Jutzy KR, et al. Transesophageal echocardiographic recognition of subaortic complications in aortic valve endocarditis: clinical and surgical implications. Circulation 1992;86:353-62.

10 Daniel WG, Mugge A, Martin RP, Lindert O, Hausmann $\mathrm{D}$, Nonnast-Daniel $\mathrm{B}$, et al. Improvement in the diagnosis of abscess associated with endocarditis by transesophageal echocardiography. $N$ Engl f Med 1991;324: 795-800.

11 Seward JB, Khandheria BK, Oh JK, Abel MD, Hughes RW Jr, Edwards WD, et al. Transesophageal echocardiography: technique, anatomical correlations, implementation, and

12 Saner HE, Asinger RW, Homans DC, Helseth HK, Elsperger KJ. Two-dimensional echocardiographic identification of complicated aortic root endocarditis: implications for surgery. $₹ \mathrm{Am}$ Coll Cardiol 1987;10:859-68.

13 Perry GJ, Helmcke F, Nanda NC, Byard C, Soto B. Evaluation of aortic insufficiency by Doppler color flow Evaluation of aortic insufficiency by Dopp
mapping. $\mathcal{A}$ Am Coll Cardiol 1987;9:952-9.

14 Rohmann S, Seifert T, Erbel R, Jakob H, Mohr-Kahaly S, Makowski T, et al. Identification of abscess formation in 
native-valve -endocarditis using transesophageal echocardiography: implications for surgical treatment. Thorac Cardiovasc Surg 1991;39:273-80.

15 John RM, Pugsley W, Treasure T, Sturridge MF, Swanton RH. Aortic root complications of infective endocarditis-influence on surgical outcome. Eur Heart $₹ 1991$; 12:241-8.

16 Wong CM, Oldershaw P, Gibson DG. Echocardiographic demonstration of aortic root abscess after infective endocarditis. Br Heart $\mathcal{f} 1981 ; 46: 584-6$.

17 Ellis SG, Goldstein J, Popp RL. Detection of endocarditis associated perivalvular abscesses by two-dimensional echocardiography. $\mathcal{F}$ Am Coll Cardiol 1985;5:647-53.

18 Neimann JL, Danchin N, Godenier JP, Villemot JP, Faivre G. Two-dimensional echocardiographic recognition of aortic valve ring abscess. Eur Heart $\mathcal{f}$ 1984;5(suppl C):59-65.

19 Mohr-Kahaly S, Kupferwasser I, Erbel R, Wittlich N, Iversen $S$, Oelert $H$, et al. Value and limitations of transesophageal echocardiography in the evaluation of aortic prostheses. $\mathcal{F}$ Am Soc Echocardiogr 1993;6:12-20.

\section{SHORT CASES IN CARDIOLOGY}

A

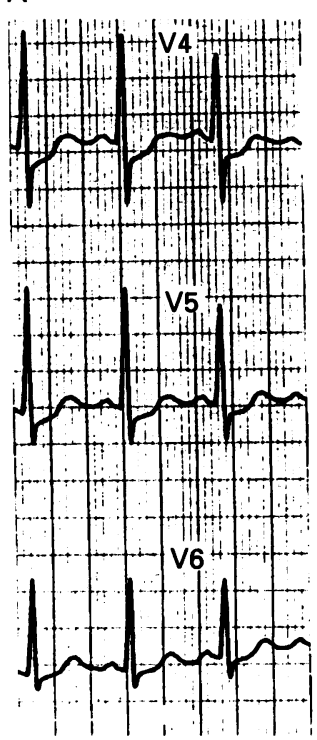

B

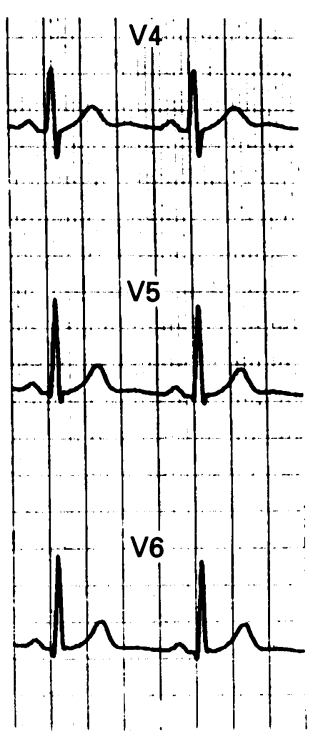

Electrocardiogram (A) during administration of salbutamol $2.5 \mathrm{mg}$ by nebuliser and (B) an hour later.

\section{Department of Cardiology, St George's Hospital H E Montgomery J Gill C W Pumphrey Correspondence to: Dr H E Montgomery, c/o Hatter Institute for Cardiovascular Research, University College Hospital, Gniversity College Hosp Wower Street,}

\section{Unsuspected coronary artery disease revealed by administration of nebulised salbutamol}

\author{
H E Montgomery, J Gill, C W Pumphrey
}

A 29 year old man presented with an acute attack of asthma. His regular medications included inhaled ipratropium bromide and salbutamol and he had been taking oral theophylline for three days before presentation. The peak expiratory flow rate was $160 \mathrm{l} / \mathrm{min}$ rising to $350 \mathrm{l} / \mathrm{min}$ after administration of $5 \mathrm{mg}$ of nebulised salbutamol. Posteroanterior chest radiography, arterial blood gas analysis, and white cell count were unremarkable. There were no identifiable risk factors for coronary artery disease.

He was given a further three doses of 2.5 mg of nebulised salbutamol over the next $7 \mathrm{~h}$ and when the last dose was given he complained of mild chest discomfort. An electrocardiogram performed during the period of discomfort showed sinus tachycardia with upsloping ST segment depression in the septolateral leads. The pain ceased promptly when he stopped using the nebuliser, and the electrocardiogram reverted to normal (fig). Similar pains and electrocardiographic changes occurred after repeat nebuliser administration of salbutamol $12 \mathrm{~h}$ later. $\mathrm{He}$ reverted to aerosal delivery of salbutamol and did not experience further pain.

At the time of the first episode of pain serum creatine kinase was $303 \mathrm{IU} / 1$ (normal 30-250 IU/1) lactate dehydrogenase $342 \mathrm{IU} / 1$ (normal 100-200 IU/1), and the aspartate transaminase concentration was normal. Repeated estimations over the next 2 days were normal.

A week later a routine electrocardiogram remained normal and transthoracic echocardiography was normal. Treadmill exercise electrocardiography using the standard Bruce protocol showed $2 \mathrm{~mm}$ planar ST segment depression in leads V4-6, with a walking time of 12 minutes limited by fatigue. The maximal heart rate was 160 beats/min and no chest pain was reported. The same response was seen $1 \mathrm{~h}$ later after the administration of 2.5 mg salbutamol by nebuliser.

Ten days after admission, coronary angiography showed that the left anterior descending artery was occluded at its origin, filling retrogradely from the right coronary artery. Both the left circumflex and right coronary arteries were normal. Left ventricular end diastolic pressure was $16 \mathrm{~mm} \mathrm{Hg}$, and the ventriculogram seemed normal with no significant impairement of anterior wall motion.

\section{Comment}

Inhaled $\beta_{2}$ agonists increase systolic blood pressure, reduce diastolic blood pressure, and are positive inotropes

The electrocardiogram may show reduced $T$ wave amplitude and prolongation of the corrected QT interval (QTc). ${ }^{12}$ Positive chronotropic effects have been reported to hasten the onset of exercise-induced ischaemia in those with known occlusive coronary artery disease, an effect possibly heightened by steal from subendocardial to the subepicardial vessels. ${ }^{3}$ A 60 year old hypertensive smoker had a myocardial infarction while using a salbutamol nebuliser, ${ }^{4}$ and severe ischaemia was seen in three other patients with previously diagnosed ischaemic heart disease.

Our case is unusual because the patient's age, lack of risk factors, normal resting electrocardiogram and lack of prior symptoms meant that without the chance use of nebulised salbutamol coronary disease might never have been suspected. Furthermore, abnormal electrocardiographic changes occurred readily with inhaled salbutamol but only late and at much higher heart rates during exercise, suggesting a role for subendocardial steal. ${ }^{3}$ Patients in whom unusual electrocardiographic changes are seen during treatment with $\beta_{2}$ agonists should be closely examined even if the diagnosis of ischaemic heart disease seems unlikely.

1 Flatt A, Crane J, Purdie G, Beasley R, Burgess C. The cardiovascular effects of beta adrenergic agonist drugs administered by nebulisation. Postgrad Med $\mathcal{f} 1990$; 66:98-101.

2 Maesen PV, Costongs R, Smeets J, Brombacher PJ, Zweers PGMA. The effect of maximal doses of formoterol and salbutamol from a metered dose inhaler on pulse rates, ECG, and serum potassium concentrations. pulse rates, ECG, and seru
Chest 1991;99:1367-73.

3 Gaspardone A, Crea F, Kaski JC, Maseri A. Effects of beta-2 adrenoceptor stimulation on exerciseof beta-2 adrenoceptor stimulation on exercise-
induced myocardial ischaemia. Am $\mathcal{F}$ Cardiol 1991;68:

4 Shovlin CL, Tam FWK. Salbutamol nebuliser and precipitation of critical cardiac ischaemia. Lancet 1990; 336:1258.

5 Neville E, Corris PA, Vivian J, Nariman S, Gibson GJ. Nebulised salbutamol and angina. $B M F$ 1982;285:
$796-7$. 